\title{
Human Resource Risk Management Framework and Factors Influencing It
}

\section{Marco de gestión de riesgos de recursos humanos y factores que lo influyen}

\author{
Ameneh Golresan Kermani \\ $\mathrm{PhD}$ student of Human Resource Management, Department of Management, Rafsanjan Branch, \\ Islamic Azad University, Rafsanjan, Iran. \\ ORCID: https://orcid.org/0000-0002-0933-9970 \\ Malikeh Beheshtifar* \\ Associate Professor, Department of Management, Rafsanjn Branch, Islamic Azad University, \\ Rafsanjan, Iran. \\ ORCID: https://orcid.org/0000-0002-2157-288X \\ Mohammad Montazery \\ Assistant professor, Department of Management, Payam Noor University, Tehran, Iran. \\ ORCID: https://orcid.org/0000-0002-8880-4219 \\ Alireza Arabpour \\ Department of Statistics, Faculty of Mathematics and Computer, Shahid Bahonar University of \\ Kerman, Kerman Iran. \\ ORCID: https://orcid.org/0000-0002-2955-7502
}

Received 02-08-20 Revised 04-10-20

Accepted 01-11-21 On line 01-17-21

* Correspondence

Citation:

Email:m.beheshtifar@iaurafsanjan.ac.ir

Golresan Kermani A. Beheshtifar M. Montazery M. \& Arabpour A., Human Resource Risk Management Framework and Factors Influencing It. Propósitos y Representaciones, 9 (SPE1), e902. Doi: http://dx.doi.org/10.20511/pyr2021.v9nSPE1.902 


\section{Summary}

Nowadays, the importance of human resource risk in organizations has greatly increased, and some thinkers refer to it as a core competency and a key responsibility for any human resource professional. Thus, given the importance of the subject of the present article, the aim of this study is to analyze the human resource risk management framework and the factors influencing it. In this regard, using the library method, human resource risk framework was analyzed from the perspective of management science thinkers of Paul and Milcher, Ernst and Young, Meyer, Maenpaa \& Voutilainen, Rotarsko, Li and Zhang, Pandey. Then, the factors influencing human resource risk management were identified and mentioned, and Stevens' human resource risk policies and procedures were presented. Then, the perception of risk and the factors influencing attention to risk and action for it were stated. In the final section, theories related to risk perception were discussed in the form of the Wild risk-homeostasis theory (1982) and the Naatanen \& Summak zero-risk theory (1976). Studies show that human resource risk management frameworks provide a conceptual model for the systematic development and planning of human resource risk management activities. They are also useful for assessing and evaluating the level of human resource risk. These frameworks provide the basis for planning, evaluating, and implementing human resource risk management.

Keywords: Risk Management, Human Resources, Risk Perception, Training, Strategy.

\section{Resumen}

Hoy en día, la importancia del riesgo de recursos humanos en las organizaciones ha aumentado considerablemente, y algunos pensadores se refieren a él como una competencia central y una responsabilidad clave para cualquier profesional de recursos humanos. Por lo tanto, dada la importancia del tema del presente artículo, el objetivo de este estudio es analizar el marco de gestión de riesgos de recursos humanos y los factores que lo influyen. En este sentido, utilizando el método de la biblioteca, se analizó el marco de riesgo de recursos humanos desde la perspectiva de los pensadores en ciencias de la gestión de Paul y Milcher, Ernst y Young, Meyer, Maenpaa y Voutilainen, Rotarsko, Li y Zhang, Pandey. Luego, se identificaron y mencionaron los factores que influyen en la gestión del riesgo de recursos humanos, y se presentaron las políticas y procedimientos de riesgo de recursos humanos de Stevens. Luego, se expuso la percepción del riesgo y los factores que influyen en la atención al riesgo y su acción. En la sección final, las teorías relacionadas con la percepción del riesgo se discutieron en forma de la teoría de riesgo de homeostasis de Wild (1982) y la teoría de riesgo cero de Naatanen \& Summak (1976). Los estudios demuestran que los marcos de gestión de riesgos de recursos humanos proporcionan un modelo conceptual para el desarrollo sistemático y la planificación de actividades de gestión de riesgos de recursos humanos. También son útiles para evaluar y evaluar el nivel de riesgo de recursos humanos. Estos marcos proporcionan la base para planificar, evaluar e implementar la gestión de riesgos de recursos humanos.

Palabras clave: Gestión de riesgos, Recursos humanos, Percepción de riesgos, Formación, Estrategia.

\section{Introduction}

Nowadays, risk management in the field of human resources is becoming the most important issue for managers around the world, and organizations are trying to define strategies for their human resource risks (Dianti \& Zare Zidi, 2017). However, stating its high importance might not be accepted for some activists in this field and they might think that based on this 
perspective we will have negative view of human resources and its sectors, and in fact, we seek to control all sectors and activities of human resources and thus limit the creativity and innovation of employees (Romina \& Momizan, 2015). These statements are made because we do not really understand have a right perception of the risk of human resources and only develop the concept of avoiding negative issues as the concept of risk in our minds, while in the concept of risk in addition to this dimension, we pay attention to other dimension of this concept that views risk as an opportunity to try to make use of it in the best way. In this approach, we look at employees' innovation and creativity as a smart risk that is an opportunity that we must use it optimally. In fact, one of the main tasks of human resources professionals in this approach is to develop a culture that encourages these innovations (Zare Ravasan \& Dilami, 2014). The main point in human resource risk management area is to create the vision for managers that all these smart risks may not achieve their goals and this should not prevent employees from taking risk. Accordingly, with regard to the concept of risk, human resource management professionals should seek to identify the following two issues by examining the internal and external environments of the organization:

Risk that could potentially be harmful to the organization and the focus of the risk management perspective is on increasing productivity and minimizing the losses resulting from this risk. Opportunities that may be missed and ensure that the risk of losing opportunities has been minimized (Zare Ravasan \& Dilami, 2014). Regarding human resource risk, Parker (1995) states that this risk refers to a company's personnel policies such as hiring, training, motivating, and retaining employees. Human resource risks are emerged in many forms, such as the risk of losing key employees, the risk of insufficient or incorrect motivation among management staff, and so on (Nadri \& Mehrabi, 2018). Regarding employee risks, Stevens (2005) argues that in controlling employee risks, behavioral risk analysis should first be performed and then the organization's measures to allow or even reinforce behaviors related to employee risk should be controlled. For example, it does not pay attention to the way the organization plans its major changes or to issues such as communicating with employees to get their feedback on changes (Dianti \& Zare Zidi, 2017). In a study conducted by Aon Organization on 300 risk managers, among seven main risks of organizations, the risk of human capital was ranked first from their point of view and its most important indicators included hiring employees and retaining and compensating their services (Aven \& Renn, 2010). In this regard, Norons, one of the managers of this organization, states that "It is a great issue and it's growing. Human resource operational issues are also a major issue for managers in other sectors. These managers state that if they do not perform these operations (related to human resources) properly, their business strategy will fail if they do not do it properly (human resources) (Mitrofanova et al., 2017)". Given the importance of the subject of this article, the aim of this study is to analyze the human resource risk management framework and the factors influencing it.

\section{Methodology}

The present article is theoretical in terms of type and descriptive in nature, and fundamental in terms of objective. Information was collected using library methods and note taking tools by studying books and articles related to the field of information research. Investigating the human resource risk framework from the perspective of Thinkers

Paul and Milcher human resource risk framework:

The framework proposed by Paul and Milcher (2008) for human resource risk management is an integrated model that includes the three categories of environmental, strategic and operational risks of human resources as follows (Jalilvand et al., 2017): 


\section{1- Environmental risks:}

Environmental or external risks are the starting point for designing a personnel risk management system. For example, the economic environment includes factors such as the growth of the work market and the advancement of technology. The political environment includes the legal aspects of work as a source of human resource risk. Finally, risks in the cultural environment include demographic changes and changes in workers' values (Jalilvand et al., 2017).

\section{2-Strategic risks:}

Strategic orientation is one of the key elements of the human resource risk management approach that has been forgotten in the past. The main problem of strategic management at the present time is to keep the organization's strategy, structure, and human resource management aligned. Human resource risks can occur in any of these three areas (Taslimi et al., 2013).

\section{3-Operational risks:}

In 2001, the Basel Capital Treaty 2 introduced a new section of risks called operational risks. Operational risk is defined as the risk of loss due to inadequate or failed internal processes, individuals, and systems, or external events. Based on the definition, it includes an independent class of human resource risks (Taslimi et al., 2013).

\section{Ernst \& Young Human Resource Risk Framework:}

The Ernst \& Young Institute (2008) presented a comprehensive report on the risks in the field of human resources. Using the survey method and the community of senior managers, they concluded that the human resource risk cycle consists of the following four cases (Moloi, 2015):

Adaptive risk - financial risk:

-Traditional risk management areas

-Keeping the organization away from problems

-Ranking as high impact, low probability

Operational risk:

-Implementing the strategy

-Considering it as the next step in improving business

Misunderstood area of risk

-The impact and probability ranked from moderate to high

Strategic risk:

-Highest rank in terms of impact and probability 
-The area that needs the most focus

-Significant opportunity to improve the business

-Developing a general plan for improvement

Evaluation, improvement and monitoring:

-Keeping the organization away from problems

-Improving the business

\section{Meyer Human Resource Risk Framework:}

The risk management model of European Quality Management Foundation is adapted from this framework and considers the capabilities that the organization needs to manage risk. This model begins with the leadership of the human risk factor, and senior managers and executive managers of human resources are responsible for leading the human risk factor.

It means that human resource risk management is performed at the level of board of directors. Thus, the human resource manager introduces the leadership of the human risk factor to the organization (Meyer et al., 2011). This model also highlights the importance of people as key components of risk management. People have a positive or perhaps negative impact on daily risks. If managed actively, people will play a major role in creating and maintaining cultural risk. However, risk management does not happen automatically. Thus, it is important to develop a human risk factor policy and strategy for institutionalizing human resource risk in the company (Hosseinzadeh \& Bohlouli, 2016).

In the next step, the organization needs colleagues inside and outside of the organization to optimize human resource risk management. Inside the organization, it requires cooperation between different sectors (such as safety and health performance as well as the manufacturing sector). Outside the organization, it may require a variety of cooperation with key stakeholders to access accurate information and human resource management support. Finally, it can be stated that human resource risk processes are at the heart of the framework. Once the organization has developed all the capabilities of risk management, it is ready to cope with risks. Although the organization might achieve a high level of maturity to cope with risk, it will not be able to fully succeed in risk management. It can be concluded that the organization always needs creativity and continuous learning (Hosseinzadeh \& Bohlouli, 2016). According to ISO 2009 standards, organizations need human resource executive managers require an approach and framework in human resource risk management. The following example shows how organizations can define ISO in the human resource environment:

Goal

The goal is to hire competent people with appropriate knowledge and skills to do the job.

Risk

There may be skill gaps in the market and in people who are considered for the position.

Event 
The decision is to take a risk to get a job, despite the skill gap defined by the organization

\section{Results}

Employees start working and providing work at moderate level and the result is that key customers are lost and the business suffers from a weakness in human resource risk management in hiring and selecting.

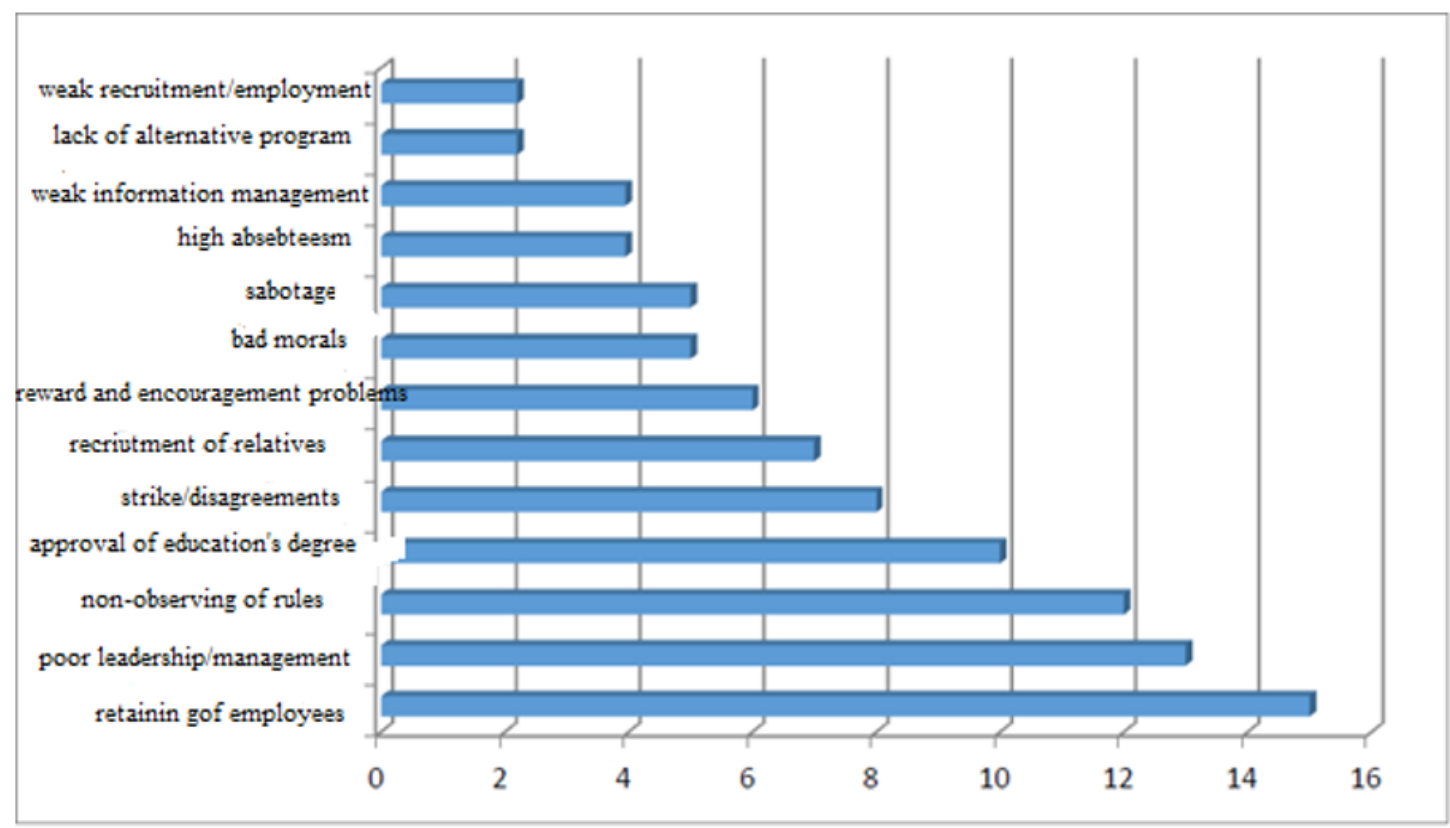

Figure 1. Different risks of human resources in 2011 in the world (Meyer et al., 2011)

Maenpaa \& Voutilainen human resource risk framework:

In their study, provide a report from the viewpoints of different people on the types of human resource risks in three classes of human capital, structural capital, and relational capital. The following table shows these viewpoints (Mitrofanova et al., 2017).

\section{Table 1.}

Classification of human resource risk from different viewpoints (Maenpaa \& Voutilainen)

\begin{tabular}{|c|c|c|c|}
\hline relational capital risk & structural capital risk & human capital risk & references \\
\hline $\begin{array}{l}\text { - Moving relationships } \\
\text { - Saying bad words } \\
\text { Poor quality of } \\
\text { products or services } \\
\text { - Weak brand or } \\
\text { reputation of company } \\
\text { - Low commitment / } \\
\text { trust of subcontractors } \\
\text { and }\end{array}$ & $\begin{array}{l}\text { - Poor research and } \\
\text { development } \\
\text { - Poor strategic planning } \\
\text { process } \\
\text { - Uncertainty about research } \\
\text { and development processes } \\
\text { - Lack of innovation, patent } \\
\text { and copyright risks related } \\
\text { to patent }\end{array}$ & $\begin{array}{l}\text {-Employee moving } \\
\text { - Insufficient training } \\
\text { of employees } \\
\text { - Discrimination } \\
\text { between employees } \\
\text { - Inexperienced } \\
\text { senior manager } \\
\text { - Crimes committed } \\
\text { by employees with } \\
\text { regard to the }\end{array}$ & $\begin{array}{l}\text { Harvey } \\
\text { and } \\
\text { Lusech } \\
\text { (1999) }\end{array}$ \\
\hline
\end{tabular}




\begin{tabular}{|c|c|c|c|}
\hline $\begin{array}{c}\text { distributors } \\
\text { - -Potential product } \\
\text { labels } \\
\text {-Risks related to the } \\
\text { strategic alliance of } \\
\text { insufficient networks }\end{array}$ & $\begin{array}{c}\text { - Lack of innovation, patent } \\
\text { and copyright risks related } \\
\text { to patent }\end{array}$ & company & \\
\hline $\begin{array}{l}\text { - Dependence on } \\
\text { subcontractors, } \\
\text { distributors and / or } \\
\text { customers }\end{array}$ & $\begin{array}{l}\text { - Flexible organizational } \\
\text { structure } \\
\text { - Insufficient knowledge / } \\
\text { information structures } \\
\text { - Non-supportive } \\
\text { organizational culture }\end{array}$ & $\begin{array}{l}\text {-Loss of } \\
\text { competence } \\
\text {-competence } \\
\text { constraint } \\
\text {-problems to guide } \\
\text { the competencies }\end{array}$ & $\begin{array}{l}\text { Copie et } \\
\text { al (2008) }\end{array}$ \\
\hline relational complexities & $\begin{array}{l}\text { - Novelty responsibility } \\
\text { - Smallness responsibility } \\
\text { - Group thinking } \\
\text { - Homogenization of senior } \\
\text { management } \\
\text { - Long-term tenure } \\
\text { - Past performance } \\
\text { - Poor knowledge } \\
\text { - The cost of ignorance } \\
\text { - Struggle for power } \\
\text { - Organizational inertia } \\
\text { - Organizational sclerosis } \\
\text { - Having a gap - doing }\end{array}$ & $\begin{array}{c}\text {--Unsuccessful } \\
\text { employment } \\
\text {-Attitudes toward } \\
\text { external duties and } \\
\text { tasks } \\
\text { - Internal competition } \\
\text { - A syndrome that } \\
\text { has not been created }\end{array}$ & $\begin{array}{l}\text { Stam } \\
(2009)\end{array}$ \\
\hline
\end{tabular}

Mousavi employees' unexpected absenteeism risk framework:

In a study of employee absenteeism risk, Mousavi, Nordin, Othman \& Sulaiman (2011) identified the risk of unexpected absenteeism as a risk that companies and organizations face, and there is no way to accurately predict risk or avoid it completely. However, it is possible to predict unexpected non-absenteeism approximately for one-month period. For such a prediction, the closest and most reliable source of undeniable information is a person's past work experience. Analyzing past history shows how reliable a person is in his or her claim. The result of such an analysis is that the system creates more accurate programs for the period after implementing the system. Thus, the company's past history should be analyzed according to the number of days it claims to be assigned to work each month. By analyzing this data set, the system can infer the way of fulfillment of the obligations of each individual, which is the gap between their claims and their fulfillment. As a result, it can reach a realistic monthly capacity that could be used to calculate the next work period (Mousavi et al., 2011).

Rotarescu human resource training framework:

Rotarescu (2011) investigated the risk of training in the field of human resources. Accordingly, he states that human resources cannot be a strategic dimension, and if it is considered an effective dimension, it will be called a fundamental dimension. Therefore, each organization develops its own human resource training strategy through appropriate training 
programs that are part of the practical and operational aspects of the organization training and the individual needs of the participants in this process.

There are several steps to develop training program based on the process model:

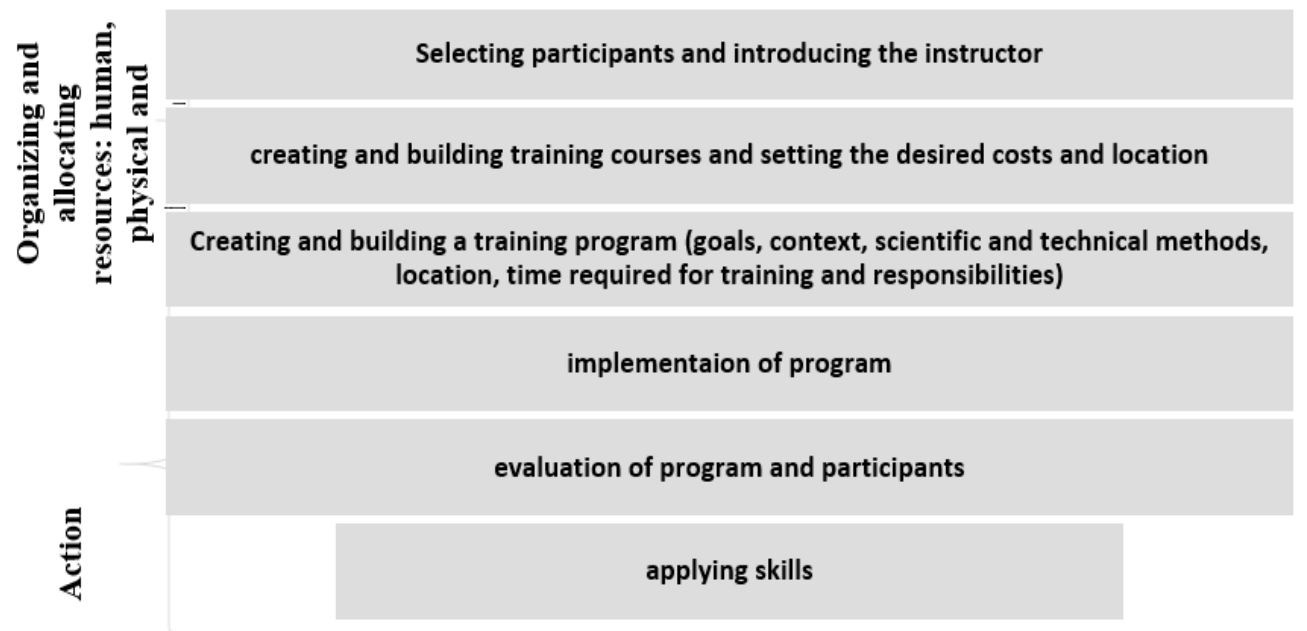

Figure 2. Human resource training risk framework (Rotărescu, 2011)

\section{Discussion}

Weakness risk framework in Li and Zhang human resource talent management:

In a study conducted by (Li \& Zhang, 2014), they examined the effect of risk and the effect of creative talents, which include the following cases:

\section{1-Risk of training failure:}

Developing creative talents requires much time and money, but money will not necessarily be returned. At the age of rapid economic development, creative talents tend to lose its role, because personnel selection may be associated with mistakes and they may not be able to develop innovative capabilities for the company or industry. In the training process, if there is no change in the various training strategies, development of innovative talents will not be appropriate. Training failure will impose much cost on company (Khoshsima \& Shahikitash, 2012).

\section{2- Risk of talent loss}

Kao Jianfeng, a professor at Remin University in China stated that talent flow is inevitable, no flow is non-natural. With the improvement of living standards, people demands have increased from low level to higher level, that is, they have changed from consumer needs to spiritual needs. In general, innovative talents generally have good spiritual benefits. According to Maslow's hierarchical theory, their needs go beyond physiological, safety, and social needs, and they are stronger than ordinary employees. Companies focus only on the applicant's work experience in employment, and rarely consider the applicant's values, which can meet the company's needs in the short term, but in the long term, it leads to increased talent loss rate. At the age of knowledge economics, innovative talents are becoming more and more important to achieve more new knowledge, and even speeding up a flow varies from minute to minute (Khoshsima \& Shahikitash, 2012).

3-Risk of cost increase 
Introducing talent leads to great wealth for companies. Innovative talents are not just about working attitudes for life, more importantly, they are ability to achieve maximum value. Level of wages to maintain talent plays a major role. All countries in the world, especially developed ones, use different tactics in talent competitions. In the face of innovative talent competition in the world, the company must strive to seize the opportunity to get creative talent. Simultaneously with attracting and investing new talent, the development of existing talents is necessary. If the company does not have a properly structured training and introduction mechanism, additional costs will increase (Akbari Alashti \& Khoshnood, 2012).

\section{4- Risk of business secrets}

The business secret refers to information and management technology, which is not known to the public. It can bring economic benefits. Sharing knowledge in one's mind is a good decision-making process and trust is the key to sharing knowledge. When an employee in a company has a kind of "psychological contract" with employees and the company, unlike legal and formal contracts, it contains a set of mutual expectations of employees and employers, and employees must keep business secrets. If information is penetrated outside the company, "psychological contract" will be less reliable. Business secrecy is a special kind of intellectual property right of many companies and is a magical weapon to win (Akbari Alashti \& Khoshnood, 2012).

Pandey health and safety risk framework:

(Pandey, 2013) argues that occupational health and safety risk is a possible physical harm caused by an adverse event caused by a given risk at workplace. Occupational risks and health and safety risks are a topic that has been investigated from various perspectives. The most prominent of these are occupational medicine, health, engineering, ergonomics, occupational psychology, employment relations, law, and economics (Pandey, 2013). For example, occupational medicine related to workplace risks and hazards with a direct and indirect impact on body function and contributes to protect employees' health against certain hazards.

Also, occupational health perspective is related to occupational health and safety risks and hazards through the identification, assessment and control of risks and hazards, including physical, chemical and biological hazards. The engineering perspective examines risks as the likelihood of harm or injury and seeks to minimize environmental hazards through engineering tools. Moreover, occupational psychology perspective is related to the injuries and diseases of individual behavior and focuses on mental discipline and individual behavior in preventing and controlling the actions (Pandey, 2013). Based on risk and control concept method, occupational health and safety risks can be defined in three broad and prominent approaches, including 1. Technical approach; 2. Psychological approach, and 3. Social approach. The technical approach defines risks as physical harms, such as injury or illness, caused by adverse events. The second approach to concept of risk and control is the psychological approach or the behavioral approach. It views risk based on the individual's perception and mental judgment of understanding nature and level of the risks. Finally, the third approach is the social perspective, which defines risk as the result of the quality of social groups' understanding of the potential risks, harms, and disadvantages within the social framework.

A systematic review of qualitative studies on employers' and employees' perceptions and reported processes of occupational health and safety risks shows that both groups pay much attention to occupational health risks as a phenomenon. It means that employees have a strong belief that it is their responsibility to control the health risks of the workplace, and that employers feel no responsibility for identifying and controlling the risks. We found a number of studies that examined the meaning of risk for employers and employees in relation to control, which showed that parties in general did not consider occupational health and safety risks as very dangerous, but consider them as an acceptable part of their work or non-prevented hazards (18).

Factors influencing human resource risk management:

Some of the risks identified by the incomes data services in its human resources include: 
* Risks of achieving to strategies:

- Loss of key employees

- Lack of organizational coordination - lack of synergy in the organization

- Failure in communication

- The failure of efforts to create integration in the organization

- Risks of non-compliance with the rules:

- Employment rules related to employment, counseling, termination of service ...

- Consensus on payment, working hours, health and safety

- Proper storage for retirement pensions (Fathi \& KabiriPour, 2012).

* Business / Operating Risks:

- Risk of activity continuity (poor communication, poor coherence of program)

- Loss of key employees

- Risk of contracts

- Fractures caused by mergers

*Cultural risks:

-Different values and cultural norms

-Disagreements (focus on personal interests) among senior managers

-Different ethical standards

-Unconscious assumptions about power, position, and decision-making

* Financial risks:

-Retirement pension and benefits

-Problems caused by quitting work

-Costs of losing employees

-Rules of claims

-Moving costs

-Safety and health costs (Gholjash \& Saeedi, 2016).

Steps of Stevens' Human Resources Risk Policies and Procedures (2015)

Stevens divides risk-related factors and stimuli into two categories of organizational and human factors. Organizational factors are structures and processes that affect the culture of the organization and include responsiveness frameworks, communication frameworks, and role / job design. Human factors also include human characteristics that should be considered as part of the risk management process (Stevens, 2015). Human factors include cognitive abilities such as short-term memory capabilities and problem-solving strategies, and almost all of the characteristics that affect risk-related behaviors. Individual differences, cognitive styles, attitudes, values, and beliefs are just some of the factors that can be considered in relation to risk-related behaviors (Stevens, 2015). Emphasizing the need to maintain psychological contracts with employees in the organization, Stevens (2015) refers to the following key steps in the process of formulating human resource risk policies and procedures (18): 


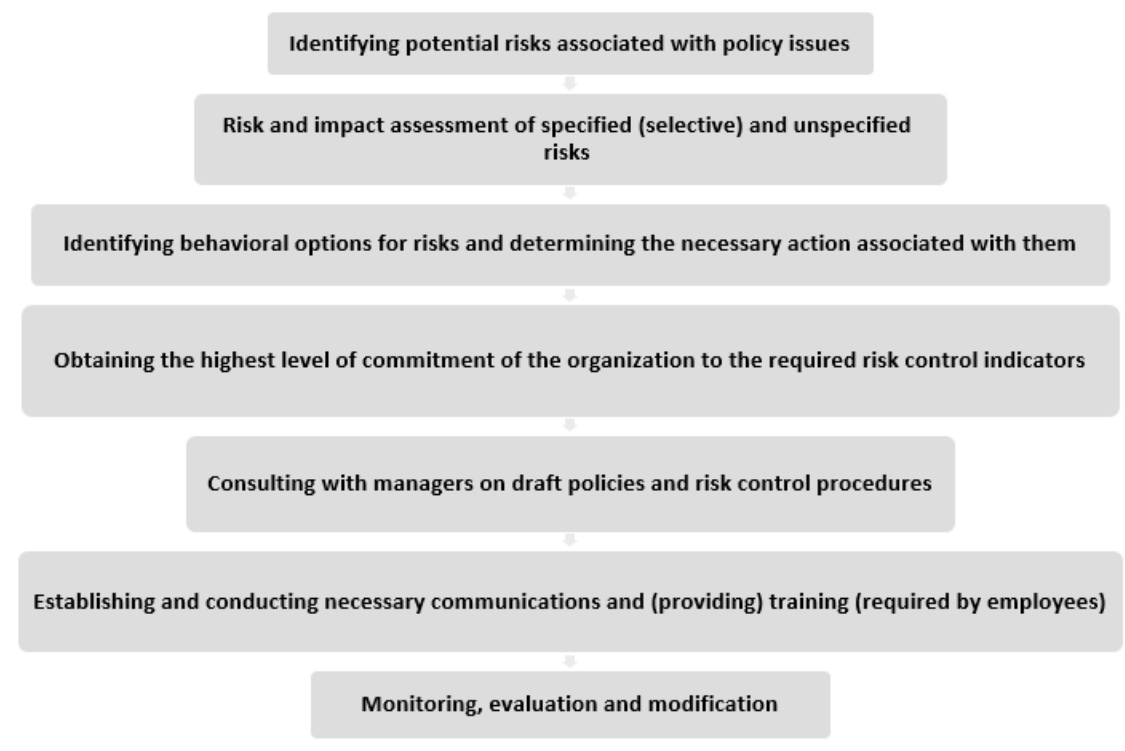

Figure 3. Steps of human resource risk steps and procedures (Stevens, 2015)

\section{Risk perception}

Risk perception is a human factor because a person's perception is not based on quantitative evidence but it is formed based on dimensions such as past experience, values, attitudes, and personality traits. The factors influencing attention to risk and action for it are as follows (Keyhan \& Haji Alirezaei, 2014):

- One's perceived level to perform tasks (how much a person feels they need to have the skills to perform their duties).

- Past experiences of negative outcomes (on organizational events and risk)

- Probability of detection and types of penalties used to break safety rules

- Fees such as gifts and promotions to keep people safe

- Fees for breaking safety rules and principles like having more free time

- Personality traits 2015).

Age: Research shows that most people are at risk, especially for men under 35 (Stevens,

Theories related to risk perception

Wild risk-homeostasis theory

Wild risk-homeostasis theory (1982) states that individuals use the above-mentioned factors to identify and maintain an individual level of risk perception for their repetitive and daily tasks. Accordingly, if the risk level of task is reduced by using better equipment or less dangerous procedures, the person is still motivated to maintain the individual level of risk perception that he or she has previously created for the task. For example, with regard to car, as cars are safer and easier to drive, the speeds and behaviors that create the same level of previous risk perception will increase (Mohagher et al., 2010).

Naatanen \& Summak zero-risk theory (1976)

With regard to risk perception, another theory has been proposed by Naatanen \& Summak (1976) under the title of zero-risk theory, which states that people are aroused to look for conditions in which perceived risk is minimal. Given the importance of taking smart risks that lead to creativity and innovation in the organization, which are nowadays vital in organizations due to the changing conditions and competitive environment of organizations, it is recommended that human resource professionals to do the following cases to promote smart risks in the organization: risk taking.

-Helping to redesign jobs / plans and procedures to create barriers to cope with negative 
- Creating wider safety boundaries (Mohagher et al., 2010).

- More effective selection and recruitment processes, and discussing on this issue where the focus is on risk management in these processes (considering the risk management conditions in the selection and recruitment processes).

- Primary training on risk issues, in which details can be provided based on the organization's vision, values and strategies related to risk management and internal control, and the way of translating them into individual responsibilities.

- Implementing development and learning programs within the organization that include the desired elements of risk management processes based on an official and legal source (Mehrani \& Akhundi, 2018).

- A strategic review and ongoing processes for role / job redesign and team development

- Ensuring that job descriptions include specific responsibilities for risk management.

- Ensuring that performance management systems include a risk management element.

- Ensuring that penalty and reward systems are included in risk management performance indicators.

-Establishing systems to identify optimal performance in compliance with the legal requirements of risk management and risky intelligent behaviors.

- Ensuring that human resource systems comply with risk management principles.

- Ensuring that disciplinary procedures include examples of unacceptable risky behaviors (Mehrani \& Akhundi, 2018).

\section{Conclusion}

At the management level, risk identification and evaluation should be considered as part of learning and development programs in relation to the tasks for which managers are accountable. A competency framework can be used for risk managers needed to manage the organization's risks. For this purpose, risk-listing tools can be used to identify specific task risks and the behaviors and processes required to control these risks. In this regard, some experts emphasize that the performance management system of managers should consider the requirements of the risk management system of the organization in relation to managers and encourage the reward system of effective risk management organization and smart risk management by them. Human resource risk management frameworks provide a conceptual model for the systematic development and planning of human resource risk management activities. They are also useful for measuring and assessing the level of human resource risk. These frameworks provide the basis for planning, evaluating, and implementing human resource risk management. In the process of risk management, the organization considers the following dual role for human resources: Human resources as a source of risk: For example, human resources may create barriers to the implementation of organizational management programs or to achieve the goals of the organization through the lack of necessary quality or error in work. Risk management: The risk management process of the organization is done by human resources themselves and in fact human resources have a key role in the implementation of the organization's systems, including risk management and so on. In the effective management of human resource risks, the following four factors are vital:

1-The organizational context in which the organization operates: for example, the activities of the organization, organization ownership status

2- Organization's public risk management policies and systems

3- People risks and human resource operations, individual and professional risks

4- Risks created by the business and operational processes of the organization. 


\section{References}

Dianti R. \& Zare Zidi A. (2017), The role of human resource management in strengthening organizational entrepreneurship, Applied Studies in Management and Development Sciences, 6(2): 1-12.

Romina A. \& Momizan A. (2015), Risks in projects of modernization and renovation of old urban textures, Case Study: Mashhad Majd project. Land Geography, 47(12): 81-92.

Zare Ravasan A. \& Dilami H. (2014), Skills needed by project managers to implement organizational resource planning systems. Information Technology Management Studies, 8 (2): 47-74.

Nadri K. \& Mehrabi L. (2018), Investigating the types of risk and risk management in the Islamic banking system, Development Strategy, 54(14): 160-181.

Aven T. \& Renn O. (2010), Risk management and governance: Concepts, guidelines and applications Springer Science \& Business Media, 16(5): 241-263.

Mitrofanova A. \& Konovalova V. \& Mitrofanova E. \& Ashurbekov R. \& Konstantin T. (2017), Human resource risk management in organization: methodological aspect, 8(2): 16-37.

Jalilvand Z. \& Soleymani F. \& Bahari J. (2017), Using clustering techniques to improve risk management efficiency in insurance companies, Management and Accounting Studies, 10(4): 258-270.

Taslimi M. \& Raei R. \& Farzinvash A. \& Barghi M. (2013), Designing and explaining the competency model of the national project managers with a focus on risk, Public administration (University of Tehran), 16(5): 57-78.

Moloi T. (2015), Human Resources Risks in a Merged Academic Institution, Journal of Governance and Regulation (print), 4(3): 155-160.

Meyer M. \& Roodt G. \& Robbins M. (2011), Human resources risk management: governing people risks for improved performance: opinion paper, SA Journal of Human Resource Management, 9(1): 1-12.

Hosseinzadeh H. \& Bohlouli N. (2016), Investigating management strategies to attract, empower and retain human resources in Miandoab Oil Products Distribution Company. Management and Accounting Studies, 3(2): 209-226.

Mousavi A. \& Nordin M. \& Othman Z. \& Sulaiman R. (2011), A Method for human resource risk management in mobile workforce brokering systems. American Journal of Applied Sciences, 8(12): 1287-1291.

Rotărescu E. (2011), The management of risk in the training of the human resources, Doctoral Dissertation, University of Sibiu, 3(2): 209-226.

Li Y. \& Zhang X. (2014), Research on the innovative talent management based on risk management theory, Journal of Chemical and Pharmaceutical Research, 6(4): 413-419.

Khoshsima R. \& Shahikitash M. (2012). The effect of credit, operational and liquidity risks on the efficiency of the Iranian banking system. Planning and Budgeting, 119(17): 69-96.

Akbari Alashti T. \& Khoshnood Z. (2012), Pre-Loss Review; Evolution in the principles of liquidity risk management in the shadow of the financial crisis. Economic News, 138(10): 122-123.

Pandey B. (2013), Understanding of occupational health and safety risks and participatory practices in small businesses. Doctoral Dissertation, Massey University, 23(9): 118-124.

Fathi S. \& KabiriPour V. (2012), Investigating the various dimensions of political risk and its impact on foreign direct investment. Business Reviews, 52(1): 20-33.

Gholjash S. \& Saeedi P. (2016), An attitude towards liquidity risk management in banks, New Research in Management and Accounting, 17(3): 49-64.

Stevens J. (2015), Falls among older adults-risk factors and prevention strategies, Journal of safety research, 36(4), 409-411.

Keyhan N. \& Haji Alirezaei G. (2014), Risk management modeling in the merger and acquisition process; Valuation-related risk analysis approach using AHP Model. Stock Exchange, 11(9): 50-65. 
Mohagher A. \& Maleki M. \& Afshari M. \& Siahkali Moradi J. (2010), Using a network analysis process to identify the risk of error behaviors in work systems, Organizational Culture Management, 22(8): 5-20.

Mehrani S. \& Akhundi A. (2018), Systematic thinking and its applications in business unit risk management in accordance with Kosovo. Accounting Research, 28(8): 53-68 